\title{
O MOdElO E O ORIGiNAL NA ARTE
}

\author{
Rodrigo Queiroz
}

Nas artes visuais e na arquitetura, a inteligência criadora pode ser compreendida a partir de dois sistemas de pensamento distintos: a obra como um modelo que apresenta na sua própria imagem seus procedimentos intelectuais e formais, ou a obra como consequência de um gesto original, aspecto que garante sua condição excepcional no mundo real.

Nesta edição da Revista Pós, com maior ou menor ênfase, alguns artigos abordam os limites entre os mitos da regra e da originalidade, como podemos observar em Tipo e Caráter no discurso da arquitetura, de Ricardo Marques de Azevedo, Le Corbusier, Pierre Chareau e duas obras-primas da arquitetura moderna, de Silvia Amaral Palazzi, $A$ "Obra Getuliana" através da Revista do Serviço Público, de Márcio Vinicius Reis, e Um impasse estético em Artigas: entre o Realismo Socialista e o Concretismo, de Raphael Grazziano.

A escolha entre a forma modelar e a forma original revela o posicionamento do artista sobre a condição de sua obra no mundo. Seja nas artes visuais, seja na arquitetura, a compreensão do objeto como um modelo pressupõe a negação do caráter excepcional, inerente à obra de arte, em nome de um sistema disciplinar. Nesses termos, o valor artístico do modelo não reside em sua originalidade, mas justamente na sua capacidade de garantir a ordenação do espaço futuro a partir das postulações contidas na aparência dessa forma exemplar.

Em linhas gerais, as principais passagens da história da arte e da arquitetura ocidental revelam justamente a representação de significados opostos, tais como razão/emoção, ordem/caos, clássico/ romântico, objetividade/subjetividade, apolíneo/ dionisíaco, dórico/jônico, racionalismo/empirismo, entre outros.

Em Tipo e Caráter no discurso da arquitetura, como o próprio nome já diz, Ricardo Marques de Azevedo discorre sobre os significados de determinados conceitos fundamentais para a constituição simbólica e formal da arquitetura, como tipo, modelo e caráter, os quais podem ser compreendidos nos projetos, nas construções e, principalmente, nos documentos textuais e gráficos, conhecidos como tratados.

Durante primeira metade do século 20, a divisão histórica entre a racionalidade disciplinar e a irracionalidade intuitiva traduz-se nos caminhos distintos trilhados por determinadas vertentes da arte e da arquitetura modernas, representadas por formas de expressão opostas, como as abstrações geométrica e gestual ou as figurações cubista e expressionista nas artes visuais, e pelas produções construtivo-serial e orgânico-compositiva na arquitetura.

0 arquiteto moderno que melhor incorporará em uma mesma forma as virtudes da racionalidade do modelo e da originalidade do "gênio criador" será Le Corbusier, que tem seu principal projeto de residência unifamiliar, a Villa Savoye, retratada no segundo artigo, Le Corbusier, Pierre Chareau e duas obras-primas da arquitetura moderna. A autora, Silvia Amaral Palazzi, coteja a mais famosa maison blanche do arquiteto franco-suíço a outro paradigmático exemplar da arquitetura moderna, a Maison de Verre, de Pierre Chareau. 0 artigo aproxima as duas residências a partir de semelhanças circunstanciais como os perfis dos respectivos clientes, ambos pertencentes à alta burguesia francesa. O confronto entre o programa de necessidades, os hábitos e os costumes de uma elite ilustrada e o imperativo renovador e socializante da nova espacialidade moderna, esboçada nos projetos de Corbusier e Chareau, expõe uma das várias contradições insolúveis do pensamento moderno: a funcionalidade de uma vida idealizada no desenho como suporte para as contingências nem um pouco modernas da instituição familiar. 
Apesar da clientela semelhante, as duas residências respondem, a partir de ações opostas, à impossibilidade de sobreposição entre a relação moderna forma/espaço e o tecido urbano da cidade real: a villa de Corbusier, refugiada na porção central de um jardim, isola-se da presença de qualquer antecedente construído, e a maison de Chareau, por sua vez, volta-se para um pátio interno, sem qualquer visibilidade urbana que a faça ombrear com as demais construções nos arredores do Boulevard Saint-Germain.

Os conceitos de "modelo" e "caráter", apresentados por Ricardo Marques no artigo anterior, se aplicam a determinados exemplares da arquitetura moderna, como as residências comparadas por Silvia Palazzi. Pelo menos para a vertente construtiva da arquitetura moderna, o objeto construído guarda em sua própria constituição a condição de modelo, como a matriz exemplar de um sistema formal e espacial. A supressão do ornamental e a consequente constituição de uma aparência abstrata, sem motivos que estimulem a memória de imediato, revelam justamente o "caráter" moderno dessas construções.

Em A "Obra Getuliana" através da Revista do Serviço Público, o autor, Márcio Vinicius Reis, apresenta os vários padrões de "estilo" nos edifícios públicos construídos durante a gestão de Getúlio Vargas, da austeridade classicizante das sedes dos Ministérios da Guerra e da Fazenda à modernidade corbusieriana da sede do Ministério da Educação e Saúde Pública. Mais uma vez, percebe-se a possibilidade de leitura dos projetos a partir das noções de "modelo" e "caráter", apontadas por Marques de Azevedo.

Em Um impasse em Artigas: entre o Realismo Socialista e o estético Concretismo, Raphael Grazziano compara duas das mais conhecidas residências projetadas por Vilanova Artigas, Olga Baeta (1956) e Rubens de Mendonça (1958) na tentativa de encontrar, respectivamente, referências ao Realismo Socialista e ao Concretismo.

O Realismo Socialista, se comparado à linguagem universal construtivista, disseminada na mesma Rússia nas duas primeiras décadas do século 20, apresenta-se como um "retorno à ordem", um retorno à figuração, com o intuito de estabelecer um código de comunicação mais direto e objetivo com as massas, sem a necessidade da consciência estética disciplinar que 0 abstracionismo geométrico exige. Ao transpor e aplicar estes conceitos às duas residências analisadas, Grazziano não apenas sobrepõe os projetos às convicções políticas de Artigas, como revela a possibilidade de compreensão dos mesmos a partir de um dilema interno à própria arquitetura moderna: a escolha entre a tradição figurativa e a modernidade abstrata. As marcas das ripas de madeira nas empenas de concreto, assim como o recorte superior destas empenas na forma de um telhado de duas águas (mas com caimento assimétrico), reconhecidos como uma citação de Artigas à arquitetura popular paranaense, revelam a incorporação de elementos da tradição à forma e a superfície da arquitetura moderna, ao passo que na residência Rubens Mendonça a forma moderna presta-se como suporte para uma composição de lavra concretista definida pelos conhecidos triângulos azuis e brancos. Contudo, tais triângulos também são reveladores de mais uma contradição típica da modernidade brasileira. Diante de um sistema industrial insipiente, resta à disposição concretista reduzir-se a mera imagem resultante de uma pintura artesanal sobre a superfície da arquitetura, inclusive com um peculiar efeito de profundidade ilusionista que simula uma relação dramática entre luz e sombra, pura representação.

No artigo Em busca do tempo e dos espaços perdidos, Claudio Soares Braga Furtado estabelece relações entre o livro "Em busca do tempo perdido", de Marcel Proust, e o pensamento arquitetônico. A ambiguidade, segundo o autor, identifica a escrita de Proust, mas também os espaços da arquitetura, como próprio edifício da FAUUSP, como sua praça central, parcialmente aberta ao rés-do-chão, mas fechada, como elemento central para onde quase todos demais espaços se voltam.

Em Por quem os rios secam, Anália Amorim discorre sobre as construções desenvolvidas para a o combate à seca na região Nordeste do Brasil, assim como reflete sobre as políticas de gestão da água no Semiárido nordestino e a alocação dos recursos hídricos como instrumento da redistribuição populacional no Brasil. 
O parque agroambiental como nova categoria de sistemas de espaços livres, de Alessandra Natali Queiroz, Eugenio Fernandes Queiroga, José Roberto Merlin, apresenta os sistemas de espaços livres na região da cidade de Limeira a partir do conceito de parque regional contemporâneo. Já $O$ desenho do suporte da renovação urbana: trânsitos entre plano e projeto, de Felipe de Souza Noto, estabelece a importante diferença entre plano urbano e projeto urbano. Segundo o autor, o caráter do projeto revela-se na sua capacidade de controlar e conferir unidade, pela sua forma, às intervenções que sucedem sua implantação.

Por uma nova cultura de Design: diversidade cultural e encontro com sentidos socioambientais, de autoria de Marília Riul e Maria Cecília Loschiavo dos Santos, estabelece aproximações entre o design profissional/acadêmico e o design vernacular, tendo como objeto de análise os utensílios elaborados pelos agricultores e pescadores da região da Barra do Rio Mamanguape, no estado da Paraíba. 0 design também é tema do artigo $O$ design para estímulo a experiências territoriais com a arte, de Leandro Miletto Tonetto, Fabrício Farias Tarouco e Mônica Greggianin. Tendo como base a $9^{a}$ Bienal de Artes Visuais do Mercosul, o artigo aborda a possibilidade de integração entre o indivíduo, a arte e o território a partir do desenvolvimento de ações artísticas que se incorporem ao meio urbano e que, consequentemente, transformem a relação cotidiana deste indivíduo com a cidade.
A edição 37 da Revista Pós marca seus vinte e cinco anos de existência. Fundado em 1990, este periódico, pertencente ao Programa de PósGraduação da FAUUSP, trilha um caminho de crescente disseminação do conhecimento e contínuo aperfeiçoamento. Este é o primeiro número da revista com todos os artigos integralmente publicados em dois idiomas (português/inglês) na versão on line. A versão integral em língua estrangeira certamente resultará em uma circulação internacional mais efetiva e consistente da revista. Os números revelam o exponencial crescimento do acesso à versão on line da Revista Pós. Em 2013 foram realizados 6.729 downloads de artigos completos, em 2014, 41.302 e apenas o primeiro trimestre de 2015 já contabiliza 35.298 downloads. A seguir a curva ascendente, somada ao novo advento de ser uma revista bilíngüe a partir desta edição, é razoável prever que ultrapassaremos a marca de 100 mil downloads até o final de 2015. Tais informações apenas comprovam a excelência da Revista Pós e a relevância de seus conteúdos, concernentes às áreas da Arquitetura, do Urbanismo e do Design.

Boa Leitura

Rodrigo Queiroz

Editor-Chefe

roqueiro@usp.br 